(c) American Dairy Science Association, 2004.

\title{
Expression of the Peptidoglycan Recognition Protein, PGRP, in the Lactating Mammary Gland
}

\author{
S. R. Kappeler, C. Heuberger, Z. Farah, and Z. Puhan \\ Laboratory of Dairy Science, Institute of Food Science, \\ Swiss Federal Institute of Technology, $\mathrm{CH}-8092$ Zurich, Switzerland
}

\begin{abstract}
The peptidoglycan recognition protein, PGRP, known as an intracellular component of neutrophils, has been isolated from camel (Camelus dromedarius) milk by acid precipitation followed by heparin-sepharose affinity chromatography of the supernatant. The mean concentration in milk was about $120 \mathrm{mg} / \mathrm{L}$. It decreased during lactation by $19 \%$ and increased in the event of severe mastitis by $45 \%$. The protein bound to lactic acid bacteria and other gram-positive bacteria with an affinity similar to that reported for the human and murine orthologs, although the isoelectric point of the molecule was distinctly higher at $\mathrm{pH}$ 9.02. The N-terminus of mature camel PGRP was determined as $\mathrm{NH}_{2}-$ ArgGluAspProPro- $\mathrm{CO}_{2} \mathrm{H}$. Calculated and measured molecular masses were both $19.1 \mathrm{kDa}$, excluding the possibility of posttranslational modifcation or binding of cation ligands. The peptide probably builds a homotrimer at high concentration. The corresponding mRNA was isolated from lactating mammary gland tissue, and $5.3 \mathrm{kbp}$ of the corresponding gene was sequenced. Similarities were found to the camel lactoferrin gene with regard to sites of expression and to the region $5^{\prime}$ upstream to the gene.
\end{abstract}

(Key words: camel milk, lactating mammary gland, peptidoglycan recognition protein)

Abbreviation key: MALDI-MS = matrix-assisted laser desorption/ionization mass spectrometry, pglyrp = gene for the peptidoglycan recognition protein (short pglyrp is synonymous to murine tumor-associated gene 7 and human tnfsf3l), PGRP = peptidoglycan recognition protein (the short variant is synonymous to murine tumor-associated gene 7 and bovine oligosaccharidebinding protein).

\section{INTRODUCTION}

The ability of milk to protect the offspring against various diseases is based on factors that belong primar-

Received October 6, 2003.

Accepted March 27, 2004.

Corresponding author: S. R. Kappeler; e-mail: stefan.kappeler@ alumni.ethz.ch. ily to the innate and adaptive immune systems. The cellular and humoral components of the latter system, such as leukocytes, immunoglobulins, and the complement system, are selectively imported from serum by intracellular routing (Praetor et al., 1999). On the other hand, the components of the first line host defense are mainly synthesized in the lactating mammary gland, conferring antimicrobial protection to the newborn. Among these factors, pattern-recognition proteins, such as lactoferrin, which binds to lipopolysaccharides of gram-negative bacteria, and lysozyme $\mathrm{C}$, which binds and hydrolyzes peptidoglycans, preferably of gram-positive bacteria, exhibit antimicrobial, immunomodulating, and antiinflammatory activities, and are synthesized in the lobuloalveolar tissue of the lactating mammary gland. Lysozyme C, a 1,4- $\beta-N$-acetylmuramidase closely related to $\alpha$-lactalbumin, is expressed in the functionally differentiated, lactating epithelium, in contrast to lactoferrin, which is predominantly expressed in developing, resting, and regressing tissue (Molenaar et al., 1992).

Short peptidoglycan recognition protein (PGRP) is a soluble, conserved pattern-recognition protein of vertebrates and invertebrates that binds to bacterial peptidoglycan with similar specificity, but with a higher affinity than lysozyme C (Liu et al., 2000). It has been previously detected in different mammalian tissues, such as spleen and lung (Kustikova et al., 1996), but it has not yet been isolated from milk. Expression of the gene for short peptidoglycan recognition protein (pglyrp) has been conversely discussed; the expression of the human, bovine, and murine variants exclusively in polymorphonuclear leukocytes and bone marrow stem cells, accompanied by intracellular storage in cytoplasmic granules, was demonstrated (Liu et al., 2000; Tydell et al., 2002). Low levels of pglyrp expression have been detected in different human and murine tissues (Kang et al., 1998; Liu et al., 2001). The corresponding cDNA has first been cloned from 2 mammary adenocarcinoma cell lines (Kustikova et al., 1996), and a majority of murine expressed sequence tag entries related to pglyrp in GenBank are derived from mammary gland tumors. The $19 \mathrm{kDa}$ peptide is basic, monomeric, and probably aggregates to homo-trimers at higher concen- 
trations (Fornhem et al., 1996; Kiselev et al., 1998; Liu et al., 2000). Specific binding with nanomolar affinity to polymeric, noncrosslinked peptidoglycans was shown for murine PGRP (Liu et al., 2000). The molecule showed weak or no affinity to other microbial polysaccharides or to peptidoglycans of low molecular weight (Yoshida et al., 1996; Liu et al., 2000). A bacteriostatic activity toward gram-positive bacteria was reported, without any bacteriolytic or otherwise bactericidal effect, and an antiinflammatory modulation of the immune response was observed. However, in a more recent report (Tydell et al., 2002), a microbicidal effect of bovine PGRP was observed, and the protein was also effective against gram-negative bacteria and a fungal pathogen.

Our interest was to characterize camel PGRP and its binding to lactic acid bacteria and pathogenic bacteria. The regulation of pglyrp expression in the lactating mammary gland of camels is furthermore correlated with data from 68 individual milk samples, with regard to health status, incidence of bacterial infection, and lactational stage of the animals.

\section{MATERIALS AND METHODS}

\section{Milk Sample Collection}

A total of 68 samples of camel milk were collected at 2 breeding stations in Isiolo and Rumuruti in Kenya. Milk from the four quarters of the camel udders were collected separately and examined for total SCC (California mastitis test) and for bacterial growth on blood agar and Edwards agar, and in Todd-Hewitt broth. The lactational stage of the camels was between 2 and 13 mo. Additionally, 5 porcine mastitis-negative milk samples were collected on a local farmyard on the day of parturition and 3 wk thereafter. Pooled human and bovine mastitis-free raw milk samples from midlactation were obtained from a women's hospital in Zurich and from a Swiss brown cattle farm near Zurich. The milk was centrifuged at $10,000 \times g$ and at $4^{\circ} \mathrm{C}$ for 30 min, and filtered through nylon mesh. The skimmed milk was acidified by addition of $1 \%$ ( $\mathrm{vol} / \mathrm{vol}$ ) acetic acid and incubated at $37^{\circ} \mathrm{C}$ for $10 \mathrm{~min}$. Following, it was neutralized with $1 / 10$ vol. of $1 M$ sodium acetate, and centrifuged at $10,000 \times g$ and at $4^{\circ} \mathrm{C}$ for $5 \mathrm{~min}$. The supernatant, containing soluble whey proteins, was filtered through a $0.45-\mu \mathrm{m}$ screen.

\section{Heparin-Sepharose Affinity Chromatography}

Soluble whey proteins $(10 \mathrm{~mL})$ were loaded on a 1$\mathrm{mL}$ Heparin-Sepharose HiTrap column (GE Healthcare Bio-Sciences, Little Chalfont, UK). The column was washed with $20 \mathrm{~mL}$ of $0.01 M$ sodium phosphate and
$0.1 M$ sodium chloride at $\mathrm{pH}$ 7.4. Elution was performed at ambient temperature applying a linear gradient from 0.1 to $0.7 M$ sodium chloride over $37 \mathrm{~min}$. The column effluent was monitored at $280 \mathrm{~nm}$. The collected fractions were separated by 4 to $12 \%$ gradient SDS-PAGE, and proteins were detected by Coomassie staining. An additional purification step was carried out, prior to micro-sequencing and molecular mass determination, by reversed-phase HPLC on an analytical silica-coated $\mathrm{C}_{18}$-column $(5 \mu \mathrm{m}, 250 \times 4.6 \mathrm{~mm})$. Elution was performed at ambient temperature by applying a linear gradient from $0.1 \%$ trifluoroacetic acid in double-distilled, nanofiltered water to $0.1 \%$ trifluoroacetic acid in acetonitrile, at a flow rate of $1 \mathrm{~mL} / \mathrm{min}$ over $60 \mathrm{~min}$.

\section{Amino Acid N-Terminal Sequence Analysis}

Protein $(0.5 \mathrm{nmol})$ collected from the effluent of the $\mathrm{C}_{18}$-column was used directly for $\mathrm{N}$-terminal sequencing. Eluted proteins were checked for purity by SDSPAGE, applied on a trifluoroacetic acid-treated polyvinylidene-fluoride cartridge filter and dried under continuous nitrogen flow. Automated Edman degradation over 35 cycles was performed using an ABI 471A sequencer (Applied Biosystems, Foster City, CA) equipped with a 120A HPLC for online reversed-phase $\mathrm{C}_{18}$-HPLC analysis of phenylthiohydantoinyl AA derivatives.

\section{Mass Determination of PGRP}

The molecular mass of camel PGRP was determined by matrix-assisted laser desorption/ionization mass spectrometry (MALDI-MS). Protein from the effluent of the $\mathrm{C}_{18}$-column was co-crystallized with an equal volume amount of $\alpha$-cyano-4-hydroxy-cinnamic acid (5 $\mathrm{g} / \mathrm{L})$ in $0.2 \%$ trifluoroacetic acid. Co-crystallized PGRP (3 pmol) was applied to the target, and air dried at ambient temperature. A time-of-flight mass spectrometer in linear mode was used (Voyager Elite, Applied Biosystems). Spectra were recorded with a nitrogen ultraviolet laser at $337.1 \mathrm{~nm}$ and an acceleration voltage of $25 \mathrm{kV}$. The instrument was calibrated with porcine myoglobin (monomeric, $16.953 \mathrm{kDa}$ ).

\section{Quantification}

The volumes $\mathrm{V}$ of the first and the third fraction collected from heparin-sepharose chromatographic runs of camel soluble whey proteins were determined $(\mathrm{mL})$. Absorptions at $280 \mathrm{~nm}$ were measured, and the PGRP and lactoferrin concentrations $\mathrm{C}(\mathrm{mg} / \mathrm{L})$ in the respective milk samples were calculated as $\mathrm{A}_{280} \times \mathrm{M}_{\mathrm{r}} \times$ $\varepsilon^{-1} \times 10 \times \mathrm{V}^{-1}$ using extinction coefficients $\varepsilon$ of 39,050 
$\mathrm{M}^{-1} \cdot \mathrm{cm}^{-1}$ for mature PGRP, and of $84,540 \mathrm{M}^{-1} \cdot \mathrm{cm}^{-1}$ for mature lactoferrin, as determined from the primary sequence of the mature protein. The milk samples were classified with regard to lactational stage, udder health, and bacterial infections. Average concentrations and standard errors thereof were calculated for the classes built. Correlation analyses were done according to Pearson for the comparison of quantitative values and according to Spearman for the comparison of quantitative vs. qualitative values.

\section{cDNA Sequence Analysis}

Udder tissue of a lactating camel, Somali breed, was used for polyA-mRNA isolation (Oligotex Direct mRNA Kit, Qiagen GmbH, Hilden, Germany). The tissue was prepared immediately after biopsy. A sample of mRNA $(2 \mu \mathrm{g})$ was used for cDNA synthesis with the Universal RiboClone cDNA Synthesis System (Promega Corp., Madison, WI) with an oligo(dT)15 primer and EcoR I adapters. One-fifth of the resulting cDNA was ligated to $1 \mu \mathrm{g}$ of dephosphorylated $\lambda$-gt11 arms. The ligated DNA was packaged in vitro with an Escherichia coli C Packagene $\lambda$ DNA extract (Promega). All work was done according to the manufacturer's instructions. Phages were plated on $E$. coli LE 392 (Promega). The library titer was estimated at $2.6 \times 10^{5} \mathrm{pfu} / \mathrm{mL}$. A volume of $100 \mu \mathrm{L}$ was amplified and produced a lysate with a titer of $1 \times 10^{8} \mathrm{pfu} / \mathrm{mL}$. Specific DIG-11-dUTP-labeled probes (Roche) were PCR-amplified and used for library screening by nucleic acid hybridization of plaque lifts. A degenerated oligonucleotide primer (IUB standard)

\section{5'-CCCGCCTGCGGTTCNA}

THGTNCC-3' was synthesized using the information from N-terminal sequencing. The Swiss-Prot database (www.expasy.org) was searched for entries similar to the sequenced $\mathrm{N}$-terminus. The greatest similarity was found with entry Q62185, which encodes the murine tumor-associated protein TAG7, which is the murine ortholog of short PGRP. The corresponding GenBank/ EBI Data Bank entry X86374 was used for synthesis of the reverse oligonucleotide primer 5'-TGATGTTCC AGCCTCGGCCTTCAT-3'. The short PCR product obtained was used for identification of a plaque. The excised insert was ligated into a pBR322-derived plasmid and sequenced.

\section{Genomic Sequence Analysis}

A 3.3-kbp genomic sequence encompassing the region from exon I to exon III of the camel pglyrp gene was PCR amplified twice using the exon I specific oligonucleotide primer 5'-GTGCGCTACGTGGTGGTGTCGCACAC-3' and the exon III specific oligonucleotide primer $5^{\prime}$-GC
CACACCACAAGCCAGCAGATTCTG-3', low-sheared genomic DNA from white blood cells of an Arabian camel and PfuTurbo DNA polymerase (Stratagene). The products were ligated into a pBR322-derived plasmid and sequenced.

For sequence determination of the region $5^{\prime}$ upstream to the transcription start site, the same genomic DNA was completely digested with DraI. A GenomeWalker library (K1807-1; BD Biosciences, San Jose, CA) was constructed and the sequence specific primers $5^{\prime}$-GAG GGCGAGGAGAGCCCAGACGAGAAGCAC-3' and 5'AGCACGCAGTGCCGGGTCATGGCAGGCAGA-3' were designed based on information from exon I sequenced previously. A 1.7-kbp band was obtained by nested PCR, using PfuTurbo DNA polymerase and Perfect Match PCR enhancer (Stratagene, La Jolla, CA). A TESS (Transcription Element Search System) (Schug and Overton, 1997) search for potential transcription factor binding sites was done with the TRANSFAC database (version 3.3; Wingender et al., 2000), and the following parameters were used: no allowable mismatch, a minimum element length of 6 bases and a minimum log likelihood of 6 . The reliability of transcription factor sites found was $31 \%$, calculated as follows: $(\Sigma \mathrm{nP}-\Sigma \mathrm{nR}) / \Sigma \mathrm{nP}$, with $\Sigma \mathrm{nP}$ as the number of sites found per base pair of $5^{\prime}$-flanking sequence, and $\Sigma \mathrm{nR}$ as the number of sites found per base pair in 400,000 bp of randomly generated DNA-sequence.

\section{Bacterial Binding Assay}

The lactic acid bacteria Streptococcus thermophilus and Lactobacillus delbrueckii, spp. bulgaricus, the yeast Kluyveromyces marxianus, the lysozyme-sensitive strain Micrococcus luteus DSM 20030, the gramnegative enterobacteriaceae, Enterobacter agglomerans, Escherichia coli, and Staphylococcus aureus were used to study the binding of camel PGRP to bacteria. Inoculated cultures were harvested in the exponential phase at $\mathrm{OD}_{600}=0.4$, and washed twice with $10 \mathrm{mM}$ phosphate, $20 \mathrm{mM} \mathrm{NaCl}(\mathrm{pH}=7.4)$. Between 20 and $120 \mu \mathrm{L}$ of culture was centrifuged and resuspended in $40 \mu \mathrm{L}$ of the PBS containing $0.8 \mu \mathrm{g}$ of PGRP and then incubated for $30 \mathrm{~min}$ at room temperature. The bacteria were centrifuged at $4,000 \times g, 4^{\circ} \mathrm{C}$, for $10 \mathrm{~min}$, and the absorption of the supernatant was determined at 280 $\mathrm{nm}$. The bacterial pellet was resuspended in $40 \mu \mathrm{L}$ of $10 \mathrm{~m} M$ phosphate, $1 M \mathrm{NaCl}(\mathrm{pH}=7.4)$ to dissociate bound PGRP from the bacteria. The solution was centrifuged again and the absorption of the supernatant measured as before. 
A
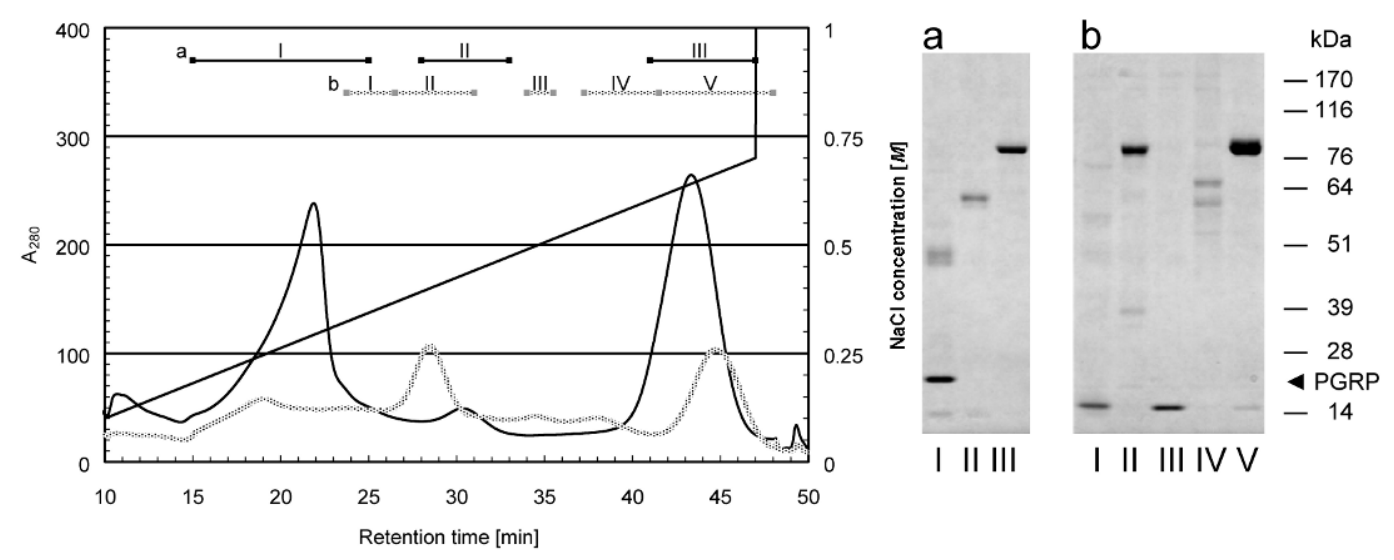

B
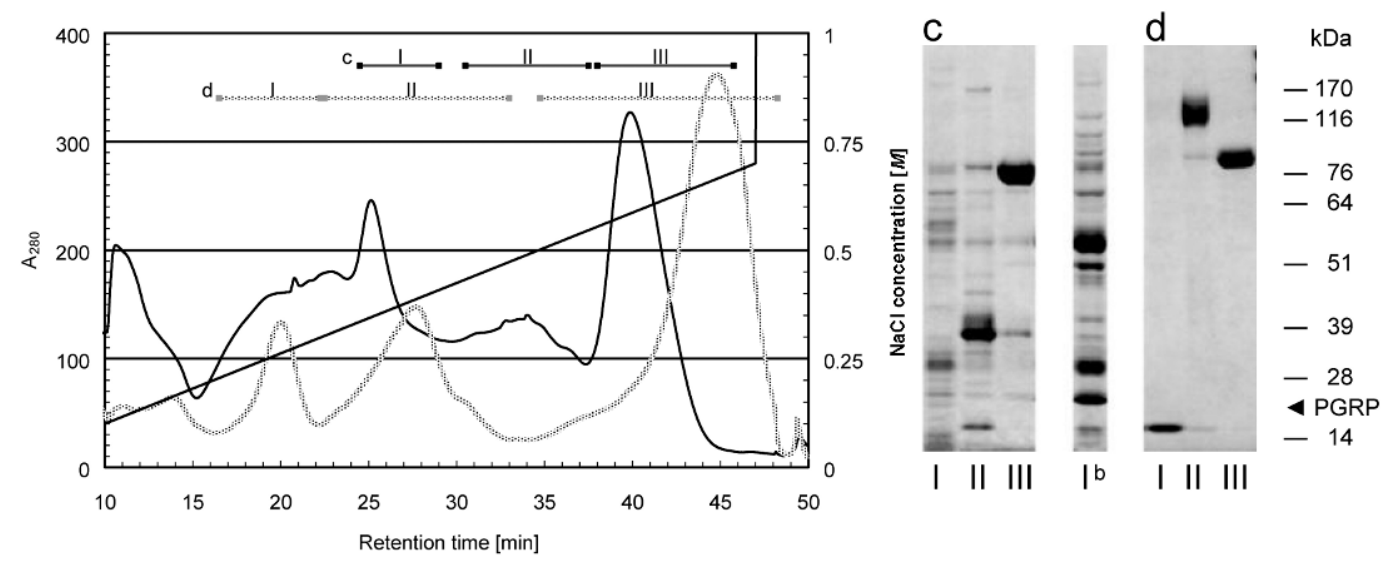

Figure 1. Isolation of the peptidoglycan recognition protein (PGRP) by heparin-sepharose chromatography. A) Elution profiles of camel (black line) and bovine (gray line) whey heparin-binding proteins; B) porcine (black line) and human (gray line) whey. Fractions were collected and separated by SDS-PAGE. a) camel fractions I-III, b) bovine fractions I-V, c) porcine fractions I-III ( ${ }^{\mathrm{b}}$ corresponds to fraction I, but from porcine colostral milk), and d) human fractions I-III.

\section{RESULTS}

\section{Isolation of PGRP from Camel Milk}

The protein was eluted from heparin-sepharose at $290 \mathrm{mM} \mathrm{NaCl}$ (Figure 1a, fraction I). The second large peak obtained was at $640 \mathrm{mM} \mathrm{NaCl}$ and contained lactoferrin (Figure 1a, fraction III). A protein with characteristics similar to those of PGRP was not isolated from bovine or human milk, and is not described in the literature as a milk component. A band with an apparent molecular weight of $19 \mathrm{kDa}$ was eluted at the same ionic strength when the column was loaded with porcine whey, and presumably corresponded to porcine PGRP (Fornhem et al., 1996). The band was more intense when colostral porcine milk was used for chromatography (Figure 1c, fraction $\mathrm{I}^{\mathrm{b}}$ ). Camel whey fraction II, which was eluted at about $400 \mathrm{mM} \mathrm{NaCl}$, contained a protein of about $59 \mathrm{kDa}$ with an unknown N-terminal sequence $\mathrm{NH}_{2}-\mathrm{NRLVG}-\mathrm{CO}_{2} \mathrm{H}$. A band of the same size was also present in fraction IV of bovine whey.

\section{cDNA and Peptide Analysis}

The N-terminal sequence of the reverse-phase purified camel protein was determined as $\mathrm{NH}_{2}$-REDPP AXGSI VPRRE WRALX SEERE RLTTP VRYPV- $\mathrm{CO}_{2} \mathrm{H}$ and was similar to the predicted $\mathrm{N}$-terminal sequence of human short PGRP (Kang et al., 1998). A cDNA clone of approximately $700 \mathrm{bp}$ that corresponded to the Nterminal sequence was obtained from a cDNA library prepared from $C$. dromedarius lactating mammary gland tissue (Panel B of Figure 2; GenBank/EBI Acc. No. AJ131676). The 5'-untranslated region contained a partial Kozak box (Kozak, 1989) in front of the start 


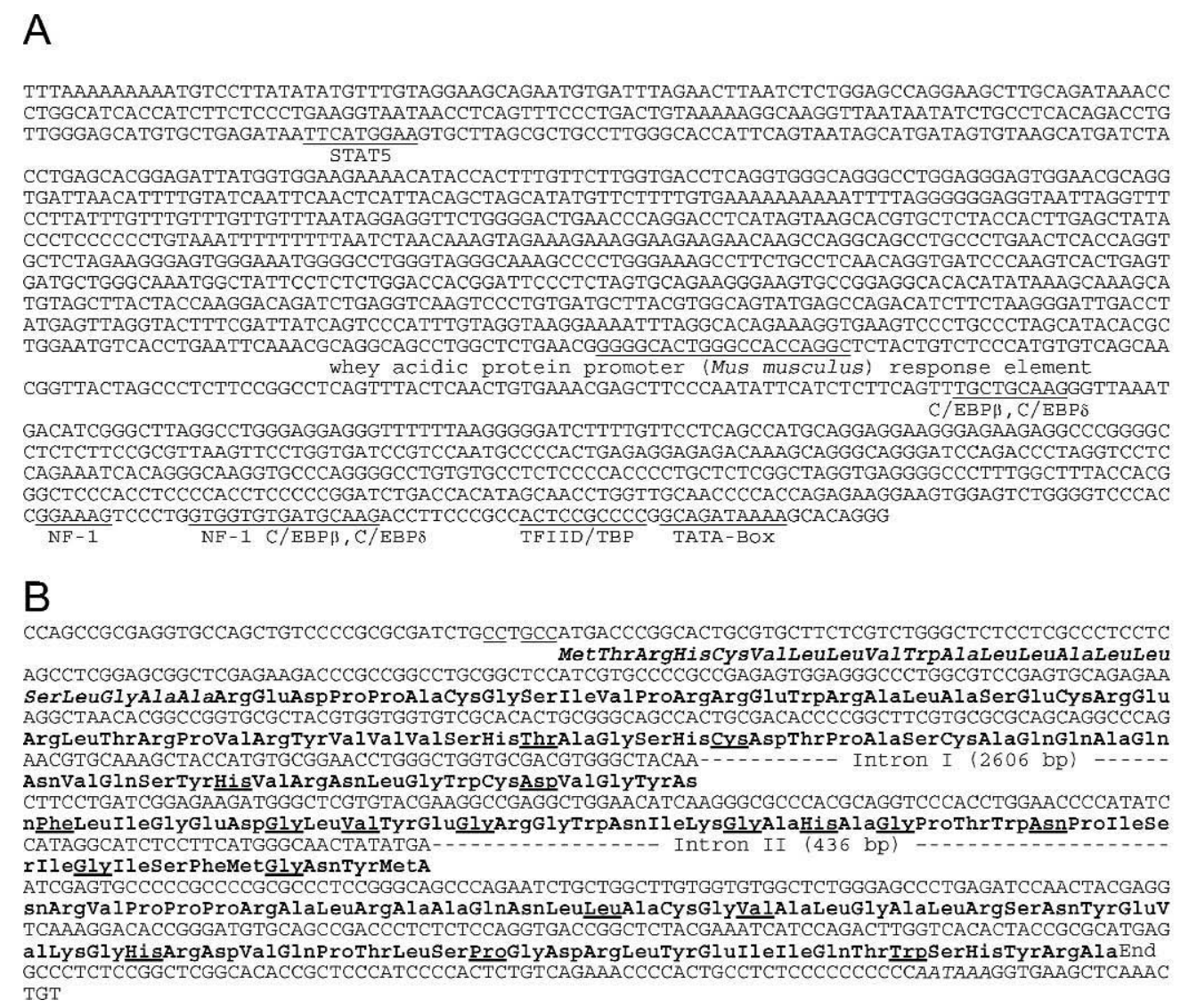

-1509
-1419
-1329
-1239
-1149
-1059
-969
-879
-789
-699
-609
-519
-429

-339
-249
-159
-69
0

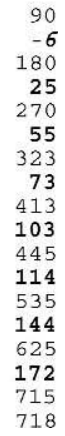

Figure 2. A) 5'-flanking region of the camel gene for the peptidoglycan recognition protein (pglyrp). Possible binding sites of transcription factors known to control the expression of milk protein genes are underlined (not presenting glucocorticoid half sites): STAT5 $=$ signal transducer and activator of transcription 5; NF-1 = nuclear factor 1; C/EBP = CAAT/enhancer-binding protein; TBP = TATA-binding protein; TFIID = Trans-acting regulatory factor IID. B) pglyrp cDNA sequence. Deduced peptide in bold, with periplasmic leader sequence in italics. The open reading frame of the cDNA sequence extended from $\mathrm{A}_{43}$ to $\mathrm{A}_{621}$, preceded by a partial Kozak-box (underlined). Polyadenylation signal in italics from $\mathrm{A}_{696}$ to $\mathrm{A}_{701}$. Numbering of the amino acid sequence begins with the first residue of the mature protein. Residues underlined are conserved in camel, murine, silkworm, and human short PGRP, human long PGRP, and T3 lysozyme.

site of protein translation. The open-reading frame coded for a peptide of 193 AA residues with a calculated molecular mass of $21.377 \mathrm{kDa}$. The combination of protein and cDNA sequencing data allowed for the prediction of the primary sequence of mature camel PGRP as a peptide $172 \mathrm{AA}$ residues in length. The calculated molecular mass of $19.143 \mathrm{kDa}$ was confirmed by a molecular mass of $19.117 \pm 0.05 \mathrm{kDa}$, as measured by MALDI-MS. Both masses were identical within measuring error, excluding the possibility of posttranslational translation (e.g., by glycosylation or by phosphorylation, or ligand binding, such as $\mathrm{Zn}^{2+}$, which is required for amidase activity of the structurally related T3 and T7 lysozymes). The Ami 2 domain, shared with the T3/T7 lysozymes and several other proteins (Letunic et al., 2002), extended from residues 30 to 156 . Sequence identity of the mature peptide was $79.4 \%$ to bovine short PGRP, $75.4 \%$ to human short PGRP, $75.2 \%$ to murine short PGRP, 37.8\% to silkworm PGRP, $29.7 \%$ to T3 lysozyme, and $38.6 \%$ to the C-terminal domain of the long variant of human PGRP. In all of these proteins, 19 residues were conserved, most of them small and hydrophobic. The calculated isoelectric point of camel PGRP was at pH 9.02, and thus distinctly higher than the calculated isoelectric points of the human and murine homologues, which were at $\mathrm{pH} 8.24$ and 7.22, respectively, but lower than porcine and bovine PGRP, which had isoelectric points higher than pH 10.5 (Fornhem et al., 1996) and 9.38 (Tydell et al., 2002). The basic nature of the protein was mostly due to a high content of arginine, but not of lysine. The arginine residues were weakly conserved between mammalian PGRP homologues. Conserved basic residues were only histidine residues $\mathrm{His}_{61}$, His $\mathrm{Hi}_{94}$, and His $_{147}$. The affinity to bacteria and heparin was completely abrogated when we partially protected the free amino groups. We partially sequenced the cDNA to porcine pglyrp (GenBank/EBI Data Bank Acc. No. 
Table 1. Background-corrected frequencies of the most prominent TF sites per $1000 \mathrm{bp}$ of $5^{\prime}$-flanking sequence, (calculated as described in Kappeler et al., 2003).

\begin{tabular}{|c|c|c|c|c|c|c|c|c|c|}
\hline \multirow{2}{*}{$\begin{array}{l}\text { Species } \\
\text { Gene product }\end{array}$} & \multicolumn{3}{|c|}{ Short PGRP } & \multirow{2}{*}{$\begin{array}{c}\text { Long } \\
\text { PGRP } \\
\text { Human }\end{array}$} & \multicolumn{3}{|c|}{ Lactoferrin } & \multicolumn{2}{|c|}{ Lysozyme C } \\
\hline & Camel & Human & Murine & & Camel & Murine & Porcine & Bovine & Porcine \\
\hline \multicolumn{10}{|l|}{ Factor $^{1}$} \\
\hline Glucocorticoid receptor & 7.8 & & 5.9 & 5.3 & 3.6 & 2.8 & 4.9 & 10.3 & 5.9 \\
\hline Activator protein 2 & 5.3 & 2.8 & & 5.9 & 8.6 & 0.9 & 3.7 & & 0.3 \\
\hline Sp1 & 5.1 & 7.0 & 0.1 & 5.7 & 4.4 & 1.3 & 6.6 & & \\
\hline c-Ets-2 & 3.4 & 1.5 & 1.5 & 0.2 & 0.8 & 0.8 & 1.2 & 2.7 & 0.2 \\
\hline Mammary activating factor & 1.1 & 0.5 & & & & 1.1 & & & 1.1 \\
\hline TFIID & 1.0 & 3.5 & & & 1.2 & 0.4 & & 4.8 & 4.8 \\
\hline Nuclear factor 1 & 0.6 & & & & & & 0.9 & 1.9 & \\
\hline Nuclear factor $\kappa \mathrm{B}$ & 0.6 & & 0.6 & 1.2 & 0.8 & & & & \\
\hline Pituitary gland specific factor $1 \mathrm{a}$ & 0.3 & 2.2 & 2.2 & & 0.3 & 1.6 & & 4.7 & 2.2 \\
\hline Yin and Yang 1 repressor & 0.1 & 1.4 & 0.1 & & & 0.1 & 0.2 & 0.7 & 0.7 \\
\hline Octamer DNA-binding protein & & 1.8 & & & & 0.6 & & 4.9 & 2.4 \\
\hline
\end{tabular}

${ }^{1} \mathrm{Sp} 1=$ Simian virus $40 \mathrm{n}$ protein 1 ; TBP = TATA-binding protein; $\mathrm{C} / \mathrm{EBP}=\mathrm{CAAT} /$ enhancer-binding protein; TFIID = trans-acting regulatory factor IID.

AJ310355) using PCR primers deduced from the camel cDNA sequence. This sequence was $84 \%$ identical to the corresponding camel sequence, and the translated peptide sequence was $82 \%$ identical. All residues, which were highly conserved amongst mammalian PGRP proteins (Tydell et al., 2002), were also found in the porcine sequence.

\section{Genetic Organization and 5'-Flanking Sequence}

The genetic organization of the camel pglyrp gene was similar to the human short pglyrp gene, with 2 intron sequences separating 3 exon sequences (Panel A of Figure 2). The first intron in both genes was considerably longer than the corresponding second intron of the silkworm ortholog (2606 vs. $188 \mathrm{bp}$ ), due to a high frequency of interspersed elements, mainly of the short mammalian interspersed repetitive element and the long L1 and L2 types. Analysis of the 1598-bp 5' flanking to camel pglyrp revealed a housekeeping gene type structure, with a weak TATA-box promoter sequence and a site potential for transcription factors similar to that of the corresponding region of camel lactoferrin (Table 1). A high frequency of sites for the glucocorticoid receptor, which is essential for gene expression in the lactating mammary gland (Rosen et al., 1999), was found in the $5^{\prime}$-flanking regions to the camel and murine gene, but not in the corresponding region to the human gene. A STAT5 site, which is indispensable for induction of gene transcription in the mammary gland by prolactin was only found in the $5^{\prime}$ region adjacent to camel pglyrp (Panel A of Figure 2). All sequences, especially the one $5^{\prime}$ adjacent to camel pglyrp, had a high probability to bind members of the erythroblast trans- formation specific family of transcription factors, which probably effect the insulin signal. The transcription factors presented underneath the intercepting line in Table $1 \mathrm{had}$ a lower frequency of occurrence in the $5^{\prime}$ flanking sequence to camel pglyrp, but have been discussed to be involved in the regulation of gene expression in the lactating udder or in the regulation of pglyrp expression in other species.

\section{Camel pglyrp Expression and Regulation}

Our interest was to find whether the expression of pglyrp in the lactating mammary gland was influenced by the health status of the udder or by the lactational stage of the mammary gland. We therefore collected and analyzed the milk of the 4 mammary quarters of each udder separately. The pathological status of 68 quarters from 17 lactating camels were recorded, the milk was tested on growth of different pathogenic strains and the total number of leukocytes and alveolar

Table 2. Number of microbial infections and elevated cell counts.

\begin{tabular}{lr}
\hline Item & $\mathrm{N}$ \\
\hline Individual udders examined & 17 \\
Quarter samples tested & 68 \\
Streptococcus infection & 6 \\
Staphylococcus infection & 6 \\
Enterobacter infection & 1 \\
Micrococcus infection & 1 \\
Subclinical mastitis & 14 \\
Elevated number of cells & $9^{\mathrm{a}}$ \\
Inflammation of udder quarter & $16^{\mathrm{a}}$ \\
\hline
\end{tabular}

${ }^{a}$ In 4 cases of quarter inflammation and elevated cell number, a bacterial infection was not found; another source of infection is therefore likely. 
Table 3. Expression levels of the peptidoglycan recognition protein gene (pglyrp) and the lactoferrin gene compared at different lactational stages.

\begin{tabular}{lrlc}
\hline Lactational period & N & PGRP [mg/L] & $\begin{array}{l}\text { Lactoferrin } \\
{[\mathrm{mg} / \mathrm{L}]}\end{array}$ \\
\hline Early lactation (1-4 mo) & 4 & $130 \pm 24$ & $68 \pm 14$ \\
Mid lactation (5-8 mo) & 19 & $111 \pm 7$ & $91 \pm 9$ \\
Late lactation (9-13 mo) & 3 & $105 \pm 7$ & $114 \pm 17$ \\
\hline
\end{tabular}

epithelial cells was counted (Table 2). In many camels, some quarters of the udder were seriously infected, whereas neighboring quarters remained healthy. The cell number was elevated in milk contaminated with nonbacterial pathogens and Streptococcus, but not in milk contaminated with other types of bacteria. Altogether, severe mastitis was diagnosed in $13.2 \%$ of cases, subclinical mastitis in $20.6 \%$, and a quarter inflammation, as judged by a veterinarian, was diagnosed in $23.5 \%$.

Furthermore, PGRP and lactoferrin from each quarter were separated by heparin-sepharose affinity chromatography and quantified. Mean values of milk from pathologically healthy and mastitis-free quarters of different lactational stages are presented in Table 3. The concentration of PGRP insignificantly decreased over the course of lactation. On the other hand, the concentration of camel lactoferrin increased by about $70 \%$ toward the end of lactation (Pearson $r=0.433 ; P<0.001$ ). A positive correlation with the severity of mastitis was observed for the concentrations of both proteins in milk (Table 4; Spearman $r=0.500 ; P<0.0001$ for PGRP, $r=$ $0.547 ; P<0.0001$ for lactoferrin). The assessed quarter inflammation also correlated positively with both protein concentrations (Spearman $r=0.367 ; P<0.005$ for PGRP, $r=0.496 ; P<0.0001$ for lactoferrin). An increase of both concentrations was also found in the case of Streptococcus infections (Spearman $r=0.535 ; P<$ 0.0001 for PGRP, $r=0.532 ; P<0.0001$ for lactoferrin), in contrast to infections from other bacteria. The lacto-

Table 4. Expression levels of the peptidoglycan recognition protein gene (pglyrp) and the lactoferrin gene compared for different pathological findings.

\begin{tabular}{lrcr}
\hline Pathological status of the udder & N & $\begin{array}{l}\text { PGRP } \\
{[\mathrm{mg} / \mathrm{L}]}\end{array}$ & \multicolumn{1}{c}{$\begin{array}{l}\text { Lactoferrin } \\
{[\mathrm{mg} / \mathrm{L}]}\end{array}$} \\
\hline No detectable inflammation & 29 & $107 \pm 5$ & $95 \pm 7$ \\
Mild inflammation & 4 & $118 \pm 6$ & $109 \pm 5$ \\
Severe inflammation & 6 & $155 \pm 17$ & $234 \pm 49$ \\
Streptococcus infection & 6 & $156 \pm 16$ & $237 \pm 47$ \\
Staphylococcus infection & 6 & $110 \pm 15$ & $105 \pm 8$ \\
Enterobacter infection & 1 & $135 \pm 135$ & $99 \pm 99$ \\
Micrococcus infection & 1 & $87 \pm 87$ & $73 \pm 73$ \\
Inflammation of nonbacterial origin & 4 & $121 \pm 11$ & $156 \pm 47$ \\
Elevated cell number & 9 & $147 \pm 13$ & $211 \pm 38$ \\
\hline
\end{tabular}

ferrin concentration increased more pronouncedly in infected milk than the PGRP concentration. This was also observed in cases of inflammation without evidence of bacterial origin. Four samples of irritated tissue without elevated cell counts showed a strong increase in the lactoferrin concentration, but only a slight increase in the PGRP concentration.

\section{Binding to Lactic Acid Bacteria}

A bacterial binding assay was carried out to determine the affinity of PGRP to lactic acid bacteria and to pathogenic bacteria often associated with clinical mastitis. Strong binding of PGRP was found to M. luteus (Figure 3, panel A). The affinity to lactic acid bacteria and to Staph. aureus was weaker. At $\mathrm{OD}_{600}=0.8$, Staph. aureus bound $22 \%$ of the PGRP supplied, corresponding to about one-third of the binding capacity of M. luteus. No binding affinity was found to gram-negative bacteria and the yeast $K$. marxianus. The relationship found between bound and free PGRP in the assay was linear.

\section{DISCUSSION}

We used heparin-sepharose chromatography to separate antimicrobial components of camel milk. We were able to isolate PGRP, a protein not yet described as a milk constituent, but did not detect lysozyme $\mathrm{C}$, either on the protein or at the mRNA level, although this protein is present in human and bovine milk. Porcine milk probably contained both PGRP and lysozyme C, as concluded from SDS-PAGE results. Antimicrobial proteins in milk most likely have a primary function in the protection of the lactating mammary gland, but may also be required to build up a functioning immune system in the newborn (Goldman, 2002). The extreme habitat and body metabolism of camels may have brought about a different immunological answer to pathogenic challenges compared with other mammals. A peculiarity, for example, is the expression of singlechain Ig. This hypothesis may also explain the absence of lysozyme in camel milk.

The regulation of antimicrobial gene expression in the lactating mammary gland depends on the primary function of the protein in milk. Lactoperoxidase, which serves as a bactericidal enzyme in milk, is rapidly downregulated in human and camel milk after parturition, but continuously expressed in bovine milk (unpublished data). The concentration of lactoferrin, on the other hand, is upregulated during lactation, changing its function as an iron-depleted, iron-scavenging agent in colostral milk toward an iron-saturated protein, which is bactericidal through an N-terminal proteolytic cleavage product (Kappeler et al., 1999). In camel milk, 
A

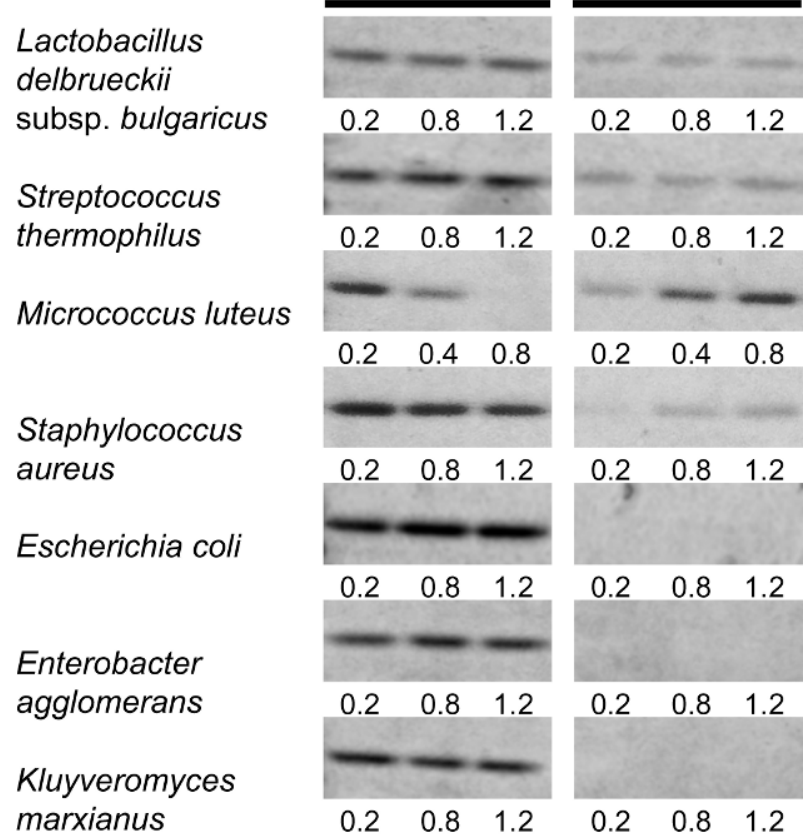

B

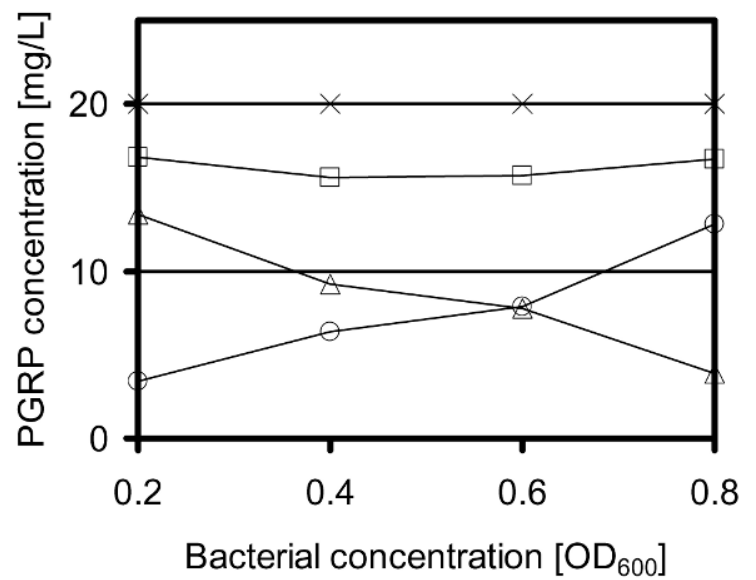

Figure 3. Camel milk peptidoglycan recognition protein (PGRP) binds to gram-positive lactic acid bacteria and pathogenic bacteria. A) Different bacterial strains and the yeast Kluyveromyces marxianus were tested on their ability to bind PGRP in low-salt $(20 \mathrm{mM})$ buffer. Numbers below the illustrations indicate the $\mathrm{OD}_{600}$ values of the assays. The protein was released by increasing the salt concentration to $1 \mathrm{M}$. Strong binding was found to the lysozyme-sensitive Micrococcus luteus. Other gram-positive bacteria exhibited about half of the binding capacity of $M$. luteus. Gram-negative bacteria and $K$. marxianus did not bind PGRP. B) Binding of $20 \mu \mathrm{g} / \mathrm{mL}$ PGRP to varying amounts of $M$. luteus. The graph shows a linear decrease of unbound protein $(\Delta)$ in the low-salt supernatant and a proportional increase of bound protein $(\mathrm{C})$ in the high-salt supernatant, when the bacterial concentration was elevated. The total of both values $(\mathrm{G})$ was about $80 \%$ of the protein added $(\mathrm{x})$.
PGRP was found to be upregulated in cases of mastitis concomitantly with lactoferrin, pointing to a function in udder protection. Furthermore, the higher protein level in early lactation indicates a role in the passive immunity of the newborn. Camel PGRP avidly bound to lactic acid bacteria, and the protein was markedly upregulated in the case of streptococcal infection, but not in other instances of mastitis. It is therefore suggested that the main function of the protein in milk is to control lactic acid bacteria.

No affinity was observed toward gram-negative bacteria and the yeast $K$. marxianus, and a binding specificity similar to that for murine PGRP was found (Liu et al., 2000). Altogether, our findings indicate a host defense function only in relation with gram-positive bacteria. In contrast, a microbicidal activity against gram-negative bacteria and even yeast has been reported for the bovine ortholog (Tydell et al., 2002). The porcine PGRP was originally isolated from nematodeinfected pigs (Fornhem et al., 1996), and a five- to sevenfold increase was reported for murine PGRP after lipopolysaccharide stimulation (Kiselev et al., 1998), indicating stimulation by and activity against several invaders. We therefore suggest that mammalian PGRP alters its target specificity under appropriate conditions, maybe by formation of heteromeric complexes with other components, as suggested for D. melanogaster PGRP long variant $\mathrm{C}$ (Choe et al., 2002). It is also possible that mammalian PGRP is able to transmit a pathogenic signal to the immune system similar to the closely related $D$. melanogaster PGRP short variant A (Michel et al., 2001).

An intriguing characteristic of the bovine ortholog is the formation of a basic bactericidal oligopeptide, Cterminal to a highly conserved leucine residue (Tydell et al., 2002). Similar basic peptides are expressed by the invertebrate immune system after transduction of the pathogenic signal by different PGRP variants (Michel et al., 2001; Choe et al., 2002; Gottar et al., 2002; Ramet et al., 2002). In milk, a direct response to a pathogenic challenge is required, and it is therefore likely that a corresponding cleavage product is also formed from camel PGRP.

The PGRP in camel ripe and porcine colostral milk is a $19-\mathrm{kDa}$ monomeric protein. The protein probably aggregates to multimeric complexes, as proposed for murine short PGRP, because we always found a faint band with an apparent molecular weight of 48 to 50 $\mathrm{kDa}$ after SDS-PAGE analysis, even when we purified fraction I from affinity chromatography by reversedphase HPLC. The intensity of the band changed proportionally to the intensity of the $19-\mathrm{kDa}$ band (Figure 1a, fraction I). Furthermore, we did not detect the binding of a divalent ligand, as found in the related phage lyso- 
zymes, although the porcine protein was described as a zinc-binding protein (Fornhem et al., 1996). Camel PGRP was eluted at $290 \mathrm{~m} M \mathrm{NaCl}$ from the affinity column, and we suppose that a combination of affinitybinding and the high isoelectric point at 9.02 has led to the retention on the column, since binding of murine PGRP, with an isoelectric point at 7.22, to soluble peptidoglycan was not inhibited by heparin, indicating a low affinity to heparin (Liu et al., 2000). We thus cannot rule out the presence of short PGRP in human or bovine milk, since the isoelectric point of both proteins is one or two degrees of magnitude lower than the isoelectric point of the camel and porcine variants.

Camel or porcine PGRP may serve as a helpful substrate for further characterization of mammalian PGRP structure and function, since it is abundantly available and can easily be purified from milk by heparin-sepharose affinity chromatography.

\section{CONCLUSIONS}

Major differences have been found in the composition of protective factors in camel milk compared with milk from true ruminants and humans. Intriguing dissimilarities are the presence of PGRP, a protein not yet detected in milk, and the absence of lysozyme C. The different composition probably comes from the evolutionary distance between the species and the extreme ecological habitat of camels. The newly detected protein probably has a main function in the protection of the lactating mammary gland but may also contribute to the passive immunization of the newborn camel.

\section{ACKNOWLEDGMENTS}

We thank P. Vögeli and M. Younan for providing swine and camel milk and the staff from CVRL, UAE for providing genomic camel DNA.

\section{REFERENCES}

Choe, K. M., T. Werner, S. Stoven, D. Hultmark, and K. V. Anderson. 2002. Requirement for a peptidoglycan recognition protein (PGRP) in relish activation and antibacterial immune responses in Drosophila. Science 296:359-362.

Fornhem, C., C. G. Peterson, and K. Alving. 1996. Isolation and characterization of porcine cationic eosinophil granule proteins. Int. Arch. Allergy Immunol. 110:132-142.

Goldman, A. S. 2002. Evolution of the mammary gland defense system and the ontogeny of the immune system. J. Mammary Gland Biol. Neoplasia 7:277-289.
Gottar, M., V. Gobert, T. Michel, M. Belvin, G. Duyk, J. A. Hoffmann, D. Ferrandon, and J. Royet. 2002. The Drosophila immune response against Gram-negative bacteria is mediated by a peptidoglycan recognition protein. Nature 416:640-644.

Kang, D., G. Liu, A. Lundström, E. Gelius, and H. Steiner. 1998. A peptidoglycan recognition protein in innate immunity conserved from insects to humans. Proc. Natl. Acad. Sci. USA 95:1007810082.

Kappeler, S. R., M. Ackermann, Z. Farah, and Z. Puhan. 1999. Sequence analysis of camel (Camelus dromedarius) lactoferrin. Int. Dairy J. 9:481-486.

Kappeler, S. R., Z. Farah, and Z. Puhan. 2003. 5'-flanking regions of camel milk genes are highly similar to homologue regions of other species and can be divided into two distinct groups. J. Dairy Sci. 86:498-508.

Kiselev, S. L., O. S. Kustikova, E. V. Korobko, E. B. Prokhortchouk, A. A. Kabishev, E. M. Lukanidin, and G. P. Georgiev. 1998. Molecular cloning and characterization of the mouse tag7 gene encoding a novel cytokine. J. Biol. Chem. 273:18633-18639.

Kozak, M. 1989. The scanning model for translation: An update. J. Cell Biol. 108:229-241.

Kustikova, O. S., S. L. Kiselev, O. R. Borodulina, V. M. Senin, A. V. Afanas'eva, and A. A. Kabishev. 1996. Cloning of the tag7 gene expressed in metastatic mouse tumors. Russ. J. Gen. 32:540-546.

Letunic, I., L. Goodstadt, N. J. Dickens, T. Doerks, J. Schultz, R. Mott, F. Ciccarelli, R. R. Copley, C. P. Ponting, and P. Bork. 2002. Recent improvements to the SMART domain-based sequence annotation resource. Nucleic Acids Res. 30:242-244.

Liu, C., E. Gelius, G. Liu, H. Steiner, and R. Dziarski. 2000. Mammalian peptidoglycan recognition protein binds peptidoglycan with high affinity, is expressed in neutrophils, and inhibits bacterial growth. J. Biol. Chem. 275:24490-24499.

Liu, C., Z. Xu, D. Gupta, and R. Dziarski. 2001. Peptidoglycan recognition proteins: A novel family of four human innate immunity pattern recognition molecules. J. Biol. Chem. 276:34686-34694.

Michel, T., J. M. Reichhart, J. A. Hoffmann, and J. Royet. 2001. Drosophila Toll is activated by Gram-positive bacteria through a circulating peptidoglycan recognition protein. Nature 414:756-759.

Molenaar, A. J., S. R. Davis, and R. J. Wilkins. 1992. Expression of alpha-lactalbumin, alpha-S1-casein, and lactoferrin genes is heterogeneous in sheep and cattle mammary tissue. J. Histochem. Cytochem. 40:611-618.

Praetor, A., I. Ellinger, and W. Hunziker. 1999. Intracellular traffic of the MHC class I-like IgG Fc receptor, FcRn, expressed in epithelial MDCK cells. J. Cell Sci. 112:2291-2299.

Ramet, M., P. Manfruelli, A. Pearson, B. Mathey-Prevot, and R. A. Ezekowitz. 2002. Functional genomic analysis of phagocytosis and identification of a Drosophila receptor for $E$. coli. Nature 416:644-648

Rosen, J. M., S. L. Wyszomierski, and D. Hadsell. 1999. Regulation of milk protein gene expression. Annu. Rev. Nutr. 19:407-436.

Schug, J., and G. C. Overton. 1997. TESS: Transcription Element Search Software on the WWW. University of Pennsylvania, PA.

Tydell, C. C., N. Y. Yount, D. Tran, J. Yuan, and M. E. Selsted. 2002. Isolation, characterization, and antimicrobial properties of bovine oligosaccharide binding protein: A microbicidal granule protein of eosinophils and neutrophils. J. Biol. Chem. 277:19658-19664.

Wingender, E., X. Chen, R. Hehl, H. Karas, I. Liebich, V. Matys, T. Meinhardt, M. Pruess, I. Reuter, and F. Schacherer. 2000. TRANSFAC: An integrated system for gene expression regulation. Nucleic Acids Res. 28:316-319.

Yoshida, H., K. Kinoshita, and M. Ashida. 1996. Purification of a peptidoglycan recognition protein from hemolymph of the silkworm, Bombyx mori. J. Biol. Chem. 271:13854-13860. 